\title{
TWEED RIVER ENTRANCE AND BYPASS SEDIMENT DYNAMICS
}

\author{
Ron Cox $^{1}$ and Dan Howe ${ }^{1}$
}

\begin{abstract}
A sediment budget analysis model was applied to the Tweed River entrance, and was used to evaluate different coastal management scenarios. Construction of training walls at the Tweed River entrance resulted in the accretion prior to 1994 of an estimated 7 million $\mathrm{m}^{3}$ along Letitia Spit, New South Wales (to the south), and erosion of beaches at the Gold Coast, Queensland (to the north). The Tweed River Entrance Sand Bypassing Project (TRESBP) was established in 1994 and is responsible for bypassing sand from south to north, through dredging campaigns and a permanent bypass jetty. The Inlet Reservoir Model was developed by Kraus (2000) as a tool to analyse morphology changes at inlets. The inputs for the model were the estimated monthly longshore sediment transport rate, and the monthly pumping and dredging volumes from the TRESBP. Side-scan sonar surveys of the entrance bathymetry were used to validate the model over the period from 2000 to 2009 . The validated model was used to examine bypass pumping strategies to manage the Letitia and Gold coast beaches, maintain navigability and minimise dredging costs. According to the model results, annual bypass pumping needs to be less than $325,000 \mathrm{~m}^{3}$ to manage the recovery of the Letitia Spit shoreline, and annual dredging of approximately $125,000 \mathrm{~m}^{3}$ is required to maintain full navigability in the Tweed River entrance.
\end{abstract}

Keywords: entrance morphology; longshore sediment transport; Inlet Reservoir Model; Tweed River

\section{BACKGROUND}

\section{History}

Training walls were built along either side of the Tweed River entrance between 1880 and 1910 to stabilise the inlet and improve navigation. Between 1962 and 1964 the training walls were extended further into the ocean (Boak et al., 2001). The high longshore sediment transport rate $\left(500,000 \mathrm{~m}^{3} /\right.$ year) resulted in significant accretion at the updrift wall on the southern (Letitia Spit) side of the entrance. Letitia Spit continued to grow, until it had reached the end of the training walls by the 1990s. Due to the interruption in longshore transport caused by the walls, the Gold Coast beaches to the north of Tweed Heads experienced severe erosion in the 1960s, 70s and 80s resulting in numerous expensive sand nourishment projects (Boak et al., 2001).

The Tweed River Entrance Sand Bypassing Project (TRESBP) was formulated in 1994 as an agreement between the New South Wales and Queensland Governments. Hyder et al. (1997) defined the objectives of the TRESBP as follows:

- New South Wales: "To establish and maintain a navigable depth of water of at least $3.5 \mathrm{~m}$ below Indian Springs Low Water (ISLW) in approach to, and within the channel entrance."

- Queensland: "To achieve a continuing supply of sand to the southern Gold Coast beaches at a rate consistent with the natural littoral drift rates updrift and downdrift of those beaches, together with the supply of additional sand to restore and maintain the recreational amenity of the beaches."

The TRESBP consisted of two stages, firstly the dredging of 4.9 million $\mathrm{m}^{3}$ of sand from the Tweed River entrance between 1995 and 1998, and secondly the construction of a permanent bypass plant that was commissioned in 2001.

The sand collection jetty is located on Letitia Spit and extends approximately $450 \mathrm{~m}$ into the Pacific Ocean (Figure 1). The water intake consists of a single submersible pump that supplies water from the lower Tweed River to the control building beside the jetty. A variable speed pump inside the control building provides high-pressure motive water to an array of eleven fixed jet pumps located at $30 \mathrm{~m}$ intervals along the jetty. The jet pumps are buried in the sand at increasing depths, and are installed on vertical rails to enable depth adjustment. When the pumps operate they create hollow cones in the seabed as they agitate and remove the surrounding sediment. These cones are essential to the operation of the bypass plant, as they form a sand trap to intercept the longshore sediment transport.

Sand comprises up to $35 \%$ of the slurry volume, and each jet pump typically delivers $110 \mathrm{~m}^{3}$ of sand per hour. With four pumps operating simultaneously, the jetty's maximum sand pumping rate is 500 $\mathrm{m}^{3}$ per hour (Pound and Leppert, 2001). During storms however, the wave-driven longshore sediment transport rate can exceed the pumping capacity of the jetty. This means some sand will bypass the jetty itself and move onto the ebb shoal in front of the Tweed River entrance, until it is dredged at a later date.

1 Water Research Laboratory, School of Civil and Environmental Engineering, University of New South Wales, Sydney, NSW, 2052, Australia 


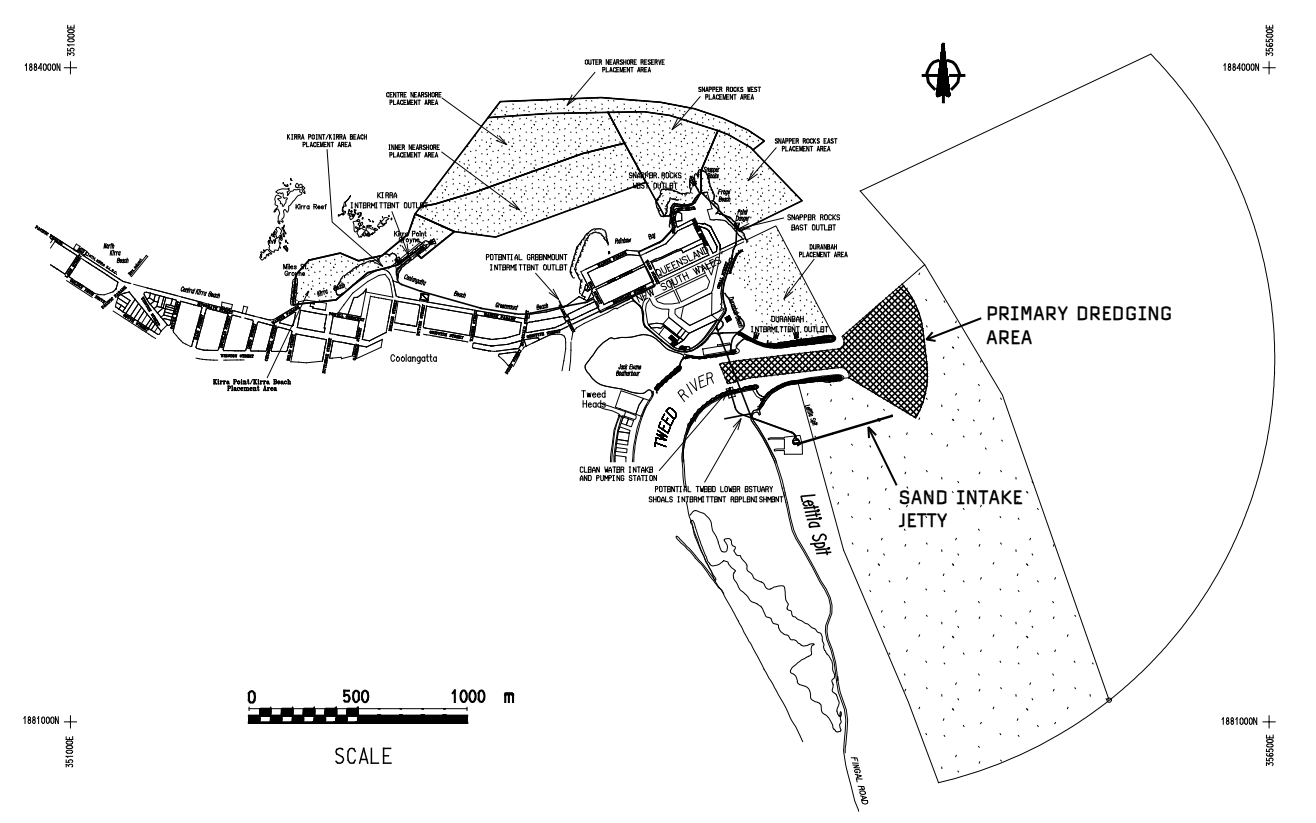

Figure 1. Locality sketch. Adapted from DLWC (2001).

Due to the scale and sensitive nature of the sand bypassing project the New South Wales Department of Lands and the Queensland Environmental Protection Agency have monitored the operations of the permanent bypass plant thoroughly since it was commissioned in 2001. In line with the TRESBP Environmental Management System (EMS) there is a community information plan designed to provide timely advice to the community with regard to operational activities (Lawson et al., 2000). This includes seabed surveys of the Tweed River entrance, sand dredging and pumping quantities, Argus imagery of the affected beaches, channel navigability reports, and surf reports for southern Gold Coast beaches. This data is published on the TRESBP website at: www.tweedsandbypass.nsw.gov.au.

\section{INLET RESERVOIR MODEL}

\section{Background}

The U.S. Army Corps of Engineers Inlet Reservoir Model was developed by Kraus (2000) as a tool to analyse morphology changes at inlets, specifically the changes in volume and sand-bypassing rate of ebb-shoals. The Inlet Reservoir Model is an aggregate model which defines morphological features by their volume alone, rather than with complex 3D bathymetry. The model is based on these assumptions:

1. Mass (sand volume) is conserved.

2. Morphological forms and the sediment pathways among them can be identified, and the morphologic forms evolve while preserving identity.

3. Stable equilibrium of the individual aggregate morphologic form(s) exists.

4. Changes in meso- and macro-morphological forms are reasonably smooth.

The model takes the estimated longshore sediment transport rate (and any human activities such as dredging and nourishing) and simulates local and regional sediment movement processes. Bannon (2008) applied the Inlet Reservoir Model to the Tweed River entrance, but did not verify the model against measured data. Howe (2009) expanded on the work of Bannon and used bathymetric surveys of the Tweed River entrance to improve and validate the model.

\section{Bathymetric surveys}

Underwater surveys have been performed by the TRESBP periodically since March 2000, covering an area within the Tweed River channel and offshore of the entrance. The surveys are recorded from a boat equipped with a side-scan sonar coupled with a GPS receiver. The vessel follows a pre-defined path taking parallel sweeps across the seabed. As of October 2009 a total of 41 surveys ( 33 for the Tweed River entrance and 8 for the lower Tweed) had been made available to the public in PDF format via the TRESBP wesite.

\section{PDF vectorisation}

The PDF surveys consisted of shaded regions, divided into $1 \mathrm{~m}$ intervals (or $2 \mathrm{~m}$ intervals for depths greater than $6 \mathrm{~m}$ ). The PDF surveys were converted to 3D polylines in CAD to create a digital terrain 


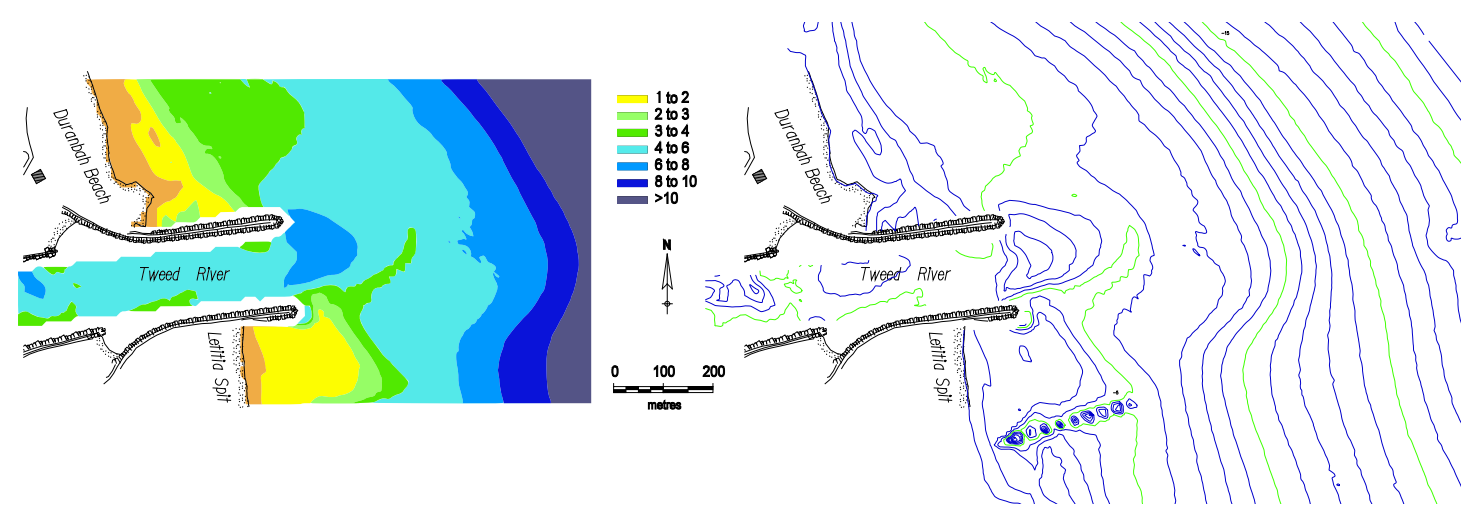

Figure 2. Survey of Tweed River entrance recorded in March, 2002 in PDF format (left) and CAD format (right). Ebb shoal is shown extending from southern training wall. Pumping cones are visible under bypass jetty.

model (DTM) for each survey. There were two problems with the PDF surveys:

- The surveys were limited in spatial extent, as they had been trimmed to fit a standard paper sheet size

- The contour intervals were too sparse to generate a representative DTM

Generating a DTM from a PDF required interpolating surfaces between adjacent contour lines. This meant any seabed undulations between contours were effectively ignored, giving unreliable results (particularly in deeper water where the contour interval was $2 \mathrm{~m}$ ).

The authors contacted the Queensland Department of Environment and Resource Management (DERM) and made a request for more detailed survey data. DERM had copies of the original surveys in plain text format with the $\mathrm{x}, \mathrm{y}, \mathrm{z}$ coordinates of each survey point. DERM made the entire survey archive available, and a unique DTM was generated in CAD format for each survey date. These DTMs were more accurate than those generated from the PDF surveys, and also covered a wider area (Figure 2).

\section{Reservoir definitions}

The purpose of obtaining the bathymetric surveys was to measure evolution of the seabed over time. The seabed was divided into discrete portions, or "reservoirs" in order to calculate the volume in each region of the inlet at the time each survey was recorded. Using CAD the sand volume in each reservoir was calculated by subtracting the DTM surface from a planar surface beneath it, using the reservoir definitions as boundaries. This allowed the volume of sand in each reservoir to be tracked through time. The planar surface from which to subtract the DTM was set for each different reservoir, depending on the reservoir's equilibrium volume.

The surveys from 2000 to 2009 were stacked above one another to try to isolate discrete morphological features in the Tweed River entrance. Six reservoirs were defined (Figure 3):

- Inner ebb shoal: This contains the small rapidly-growing ebb shoal beginning from the updrift training wall and extending across the entrance. Most of the dredging occurs in this reservoir.

- Outer ebb shoal: This contains the larger ebb shoal that is further offshore, and grows more slowly than the inner ebb shoal.

- Offshore: This is fed from the outer ebb shoal, and grows very slowly. This reservoir extended to the edge of the surveys. The survey area did not extend all the way to the depth of closure, which was observed to be more than $15 \mathrm{~m}$ below sea level.

- Entrance: This contains most of the Tweed River entrance, out to the edge of the inner ebb shoal. Some dredging occurs in this reservoir.

- Estuary: This was included as a sink for tide-driven sand to leave the entrance. It was not defined using the CAD surveys.

- Letitia Spit: This was used as the sand supply for the bypass jetty to pump from. It was not defined using the CAD surveys.

Each reservoir was given an equilibrium and an initial volume. Because the reservoirs fill with a limited growth function, the growth rate will be lower for reservoirs that are partially full. Thus the initial and equilibrium volumes for each reservoir had to be defined iteratively until they responded realistically to any sediment input.

When there is more than one pathway in the model (e.g. where the input feeds into the inner ebb shoal and Letitia Spit), coupling coefficients are used to distribute the flow of sand. The coupling coefficients to inner ebb shoal and Letitia Spit were set to 0.8 and 0.2 respectively. This means that for every $100 \mathrm{~m}^{3}$ of sand entering the model, $80 \mathrm{~m}^{3}$ is deposited in the inner ebb shoal, leaving $20 \mathrm{~m}^{3}$ for Letitia Spit. 


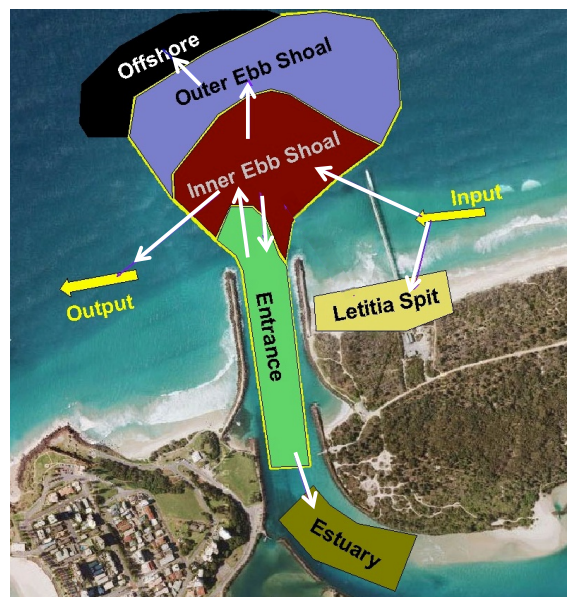

Figure 3. Reservoir and pathway definitions in Inlet Reservoir Model interface (left side of figure is north).

\section{Longshore sediment transport rate}

After defining the reservoirs and pathways, the next input for the Inlet Reservoir Model was the longshore sediment transport rate. DERM performs ongoing longshore sediment transport modelling for the Tweed River entrance using the LITPACK package, from DHI Water \& Environment. The nearshore wave climate is predicted using observations from the Tweed waverider buoy, and the net longshore transport is calculated at hourly intervals. The Queensland Government Hydraulics Laboratory provided the authors with LITPACK modelling transport rates from 2000 to 2009 . These hourly records were converted to monthly net transport volumes for use in the Inlet Reservoir Model. The annual average transport rate was almost $600,000 \mathrm{~m}^{3} /$ year (Figure 4). This was higher than the average long term transport rate of 500,000 $\mathrm{m}^{3} /$ year calculated by Delft Hydraulics Laboratory (1970) and verified by Pattearson and Patterson (1983) and Hyder et al. (1997).

The net monthly sediment transport was almost entirely in the northward direction for the period from 2000 to 2009. The Inlet Reservoir Model can simulate longshore transport in both directions, but southward transport was neglected in this study.

\section{Dredging and pumping volumes}

In addition to wave-driven sediment transport, the Inlet Reservoir Model can also simulate anthropogenic sand transport by directly adding (nourishing) or removing (dredging) sand from each reservoir. The monthly pumping volumes of the bypass jetty at Letitia Spit were obtained from the TRESBP website and were applied to the Letitia Spit reservoir as "dredging" events.

The TRESBP reports data pertaining to the volume of sand dredged from around the Tweed River entrance, but does not report the actual location from where the sand is removed. The dredging area has been defined several times, e.g. Murray et al. (1996) and Dyson et al. (2003). Some disagreement remains as to the exact boundary. The dredging area as defined by the TRESPB summary of contracts (DLWC, 2001) was used for this investigation. The majority of dredging is shared between the inner ebb shoal and

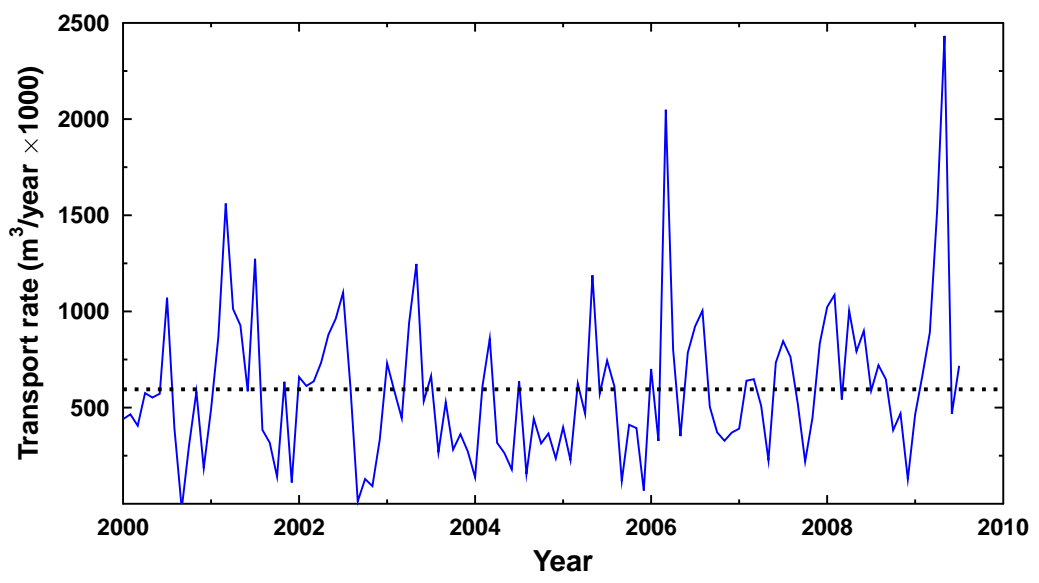

Figure 4. Monthly longshore sediment transport rate as calculated in LITPACK. Dotted line shows mean rate. 

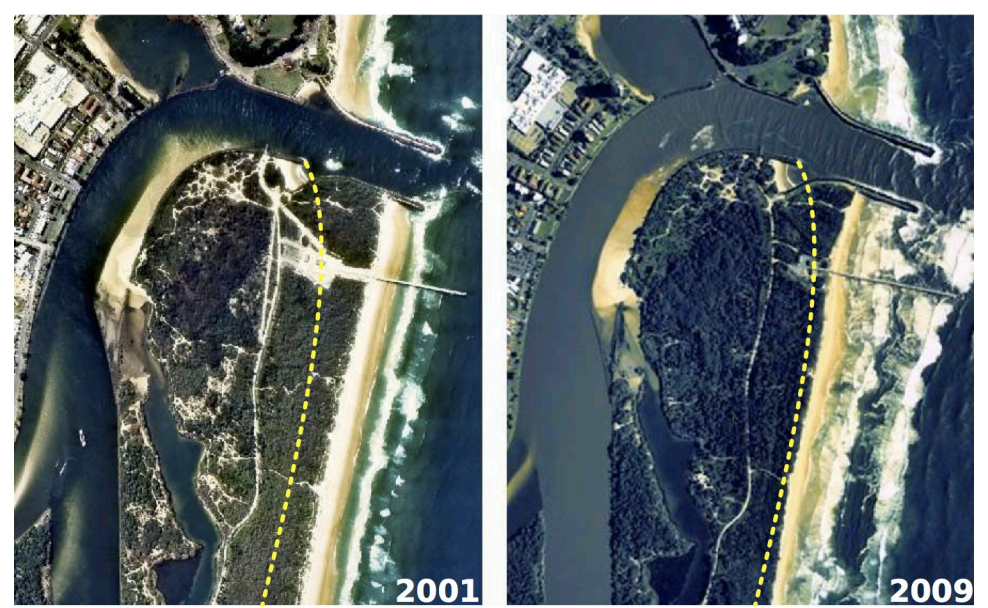

Figure 5. Shoreline of Letitia Spit in 2001 (left) and 2009 (right). Dotted line shows approximate 1962 shoreline.

the entrance reservoirs. There is some overlap into the outer ebb shoal reservoir, but this was assumed to be negligible.

A comparison of volume changes before and after dredging events indicated that roughly $20 \%$ of the total dredging volume was removed from the entrance, while the remaining $80 \%$ was removed from the inner ebb shoal. The monthly volumes for each dredging event were obtained from the TRESBP website, and were divided and allocated to the appropriate reservoir in the model.

\section{Erosion of Letitia Spit}

The accretion of Letitia Spit in the period from training wall extension in 1962 to commencement of the bypass jetty pumping in 2000 is shown in Figure 5 (left). In the initial years the bypass jetty was deliberately operating at a rate higher than the annual average so as to deliver additional sand north to Queensland. According to the Tweed River Entrance Sand Bypassing Project Agreement Act (Queensland Government, 1998) the shoreline at Letitia Spit was expected to recede during the first years of sand pumping from the bypass jetty, but there was no public information available on the actual erosion volume. In the TRESPB summary of contracts (DLWC, 2001) it was estimated that between 1965 and 1994 some 4 million $\mathrm{m}^{3}$ of sand had accreted against the southern training wall at Letitia Spit, while another 3 million $\mathrm{m}^{3}$ had been deposited either inside or offshore of the Tweed River entrance.

During validation the Inlet Reservoir Model was predicting large erosion volumes from Letitia Spit (roughly 4 million $\mathrm{m}^{3}$ of sand in the period 2000 to 2009). From aerial photographs (Figure 5) it is clear that while the Letitia shoreline has receded considerably, it does not appear to have eroded 4 million $\mathrm{m}^{3}$.

The Queensland Government Hydraulics Laboratory provided the authors with a graph of the calculated sand losses at Letitia Spit since 2000, based on beach surveys. The total loss up to July 2009 was 2.5 million $\mathrm{m}^{3}$, much less than the 4 million $\mathrm{m}^{3}$ initially predicted in the model. The data in this graph was added to the model as survey measurements for the Letitia Spit reservoir (this was fortunate, as the bathymetric surveys used for the other reservoirs could not be used for Letitia Spit).

During the validation stage the coupling coefficients between the input and inner ebb shoal were reduced over time to reflect the shoreline recession at Letitia Spit (Table 1). Before the bypass jetty was built in 2001, Letitia Spit extended almost to the edge of the Tweed River training walls and was accreting very slowly, as it had almost reached equilibrium. After pumping began however, the shoreline at Letitia Spit began to erode leaving a recess in front of the training walls for sand to be deposited once more. This increased the walls' sediment trapping efficiency and resulted in less sand deposition on the inner ebb shoal over time.

Table 1. Variation in coupling coefficients between input and inner ebb shoal over time.

\begin{tabular}{cc}
\hline Year & Coefficient \\
\hline 2000 & 0.80 \\
2002 & 0.70 \\
2003 & 0.65 \\
2004 & 0.55 \\
2006 & 0.45 \\
2007 & 0.40 \\
\hline
\end{tabular}



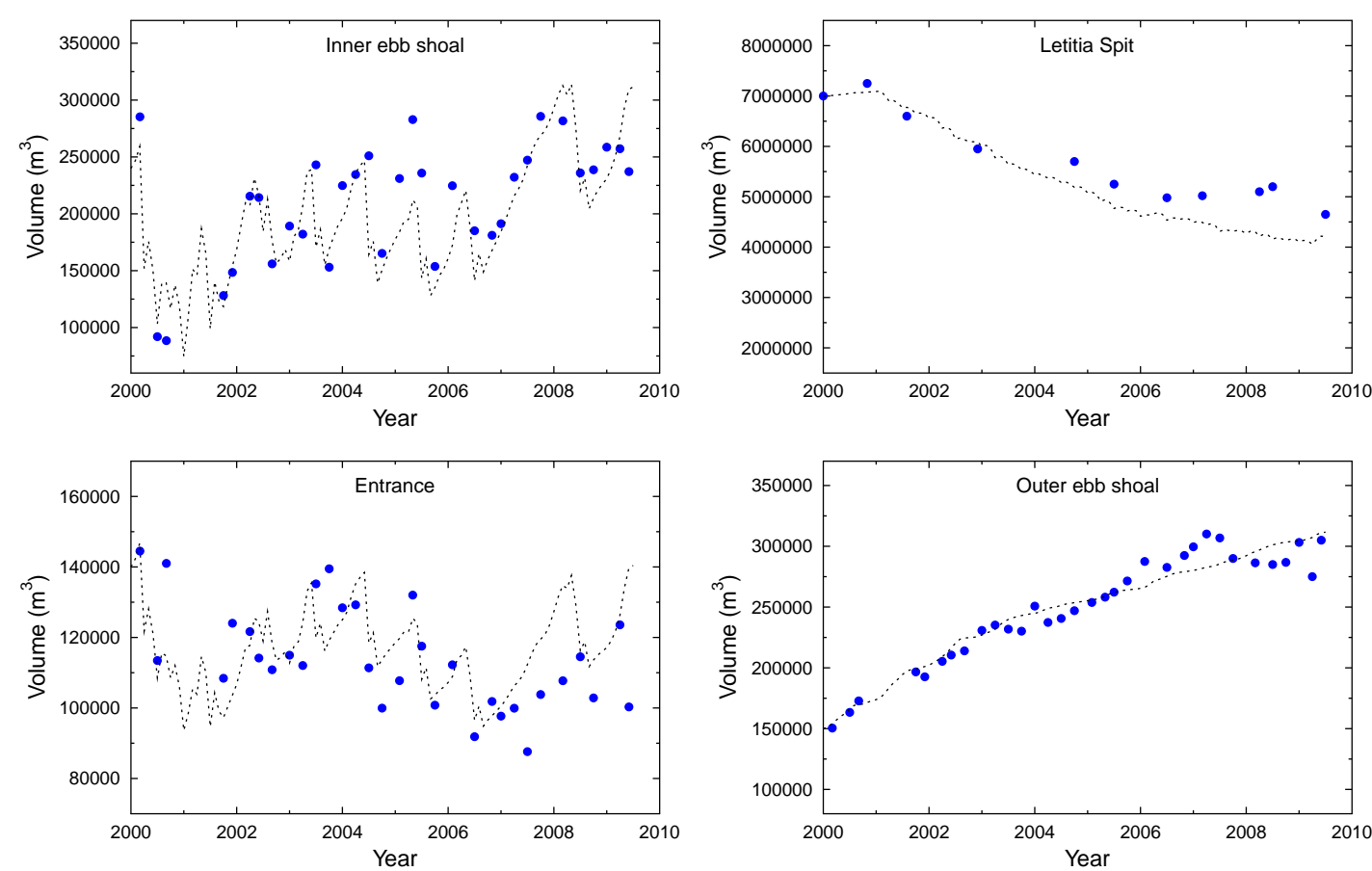

Figure 6. Calculated volumes (dashed lines) compared with measured survey volumes (dots). The sawtooth pattern in the inner ebb shoal and entrance reservoirs show the impact of dredging cycles.

\section{RESULTS}

After validation, the model agreed well with observed data for the period from 2000 to 2009 (Figure 6). The inner ebb shoal and entrance volume follows a sawtooth pattern, showing the impact of dredging cycles. Letitia Spit shows steady erosion then appears to approach equilibrium from 2007. The outer ebb shoal shows steady growth which slows over time, as it approaches its equilibrium volume.

Of the three reservoirs with bathymetric validation data, the inner ebb shoal and outer ebb shoal reservoirs had the best fit, and the entrance reservoir had the poorest fit. This reflects the complex environment in the lower Tweed, influenced by tidal flushing, floods and breaking waves. If the precise dredging locations around the river entrance were known, these errors could possibly have been reduced.

\section{FUTURE SCENARIOS}

The validated model was used to simulate two future coastal management scenarios to determine the minimum dredging frequency (Table 2). The total dredging volume was the same for both scenarios but the dredging frequency was different. Two criteria were adopted when assessing the future scenarios:

- Navigability of Tweed River entrance must be maintained

- Further erosion of Letitia Spit must be avoided

Schedule 1 of the Tweed River Entrance Sand Bypassing Agreement Act (Queensland Government, 1998) states that "The [operator] will use its best endeavours to ensure that a Clear Navigation Channel to the Tweed River is maintained". Clear Navigation Channel is defined as a "channel which has a depth below Indian Spring Low Water (ISLW) of at least 3.5 metres over a width of 70 metres and extending from an upriver limit defined by the upriver boundary of the Tweed River Bar and Entrance Area".

To determine if the Tweed River entrance was navigable, a dredging trigger volume had to be defined for both the entrance and inner ebb shoal reservoirs. All of the surveys that occurred immediately before

Table 2. Comparison of future scenarios.

\begin{tabular}{lcc}
\hline & Scenario 1 & Scenario 2 \\
\hline Dredging interval (years) & 1 & 2 \\
Sand inflow rate $\left(\mathrm{m}^{3} /\right.$ year) & 500,000 & 500,000 \\
Dredging volume $\left(\mathrm{m}^{3}\right)$ & 125,000 & 250,000 \\
Pumping volume $\left(\mathrm{m}^{3} /\right.$ year $)$ & 300,000 & 300,000 \\
Navigability & maintained & compromised \\
Letitia Spit & recovery & recovery \\
\hline
\end{tabular}



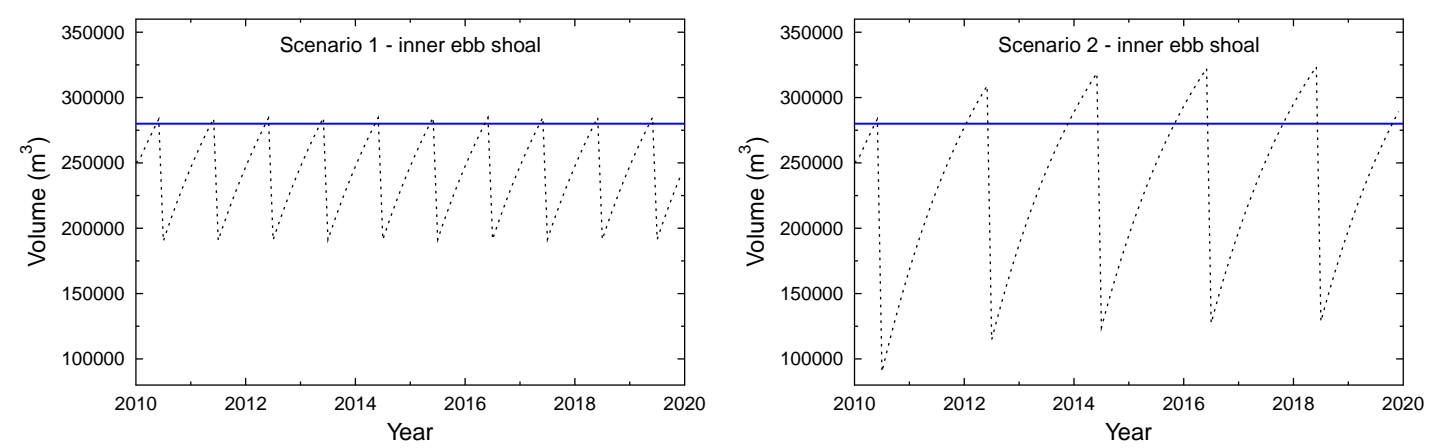

Figure 7. Calculated volumes for inner ebb shoal (dashed line), and dredging trigger volume (solid line).

a dredging campaign were selected, and the volumes of the two reservoirs on these dates were calculated. In addition a $70 \mathrm{~m}$ wide channel was drawn through the Tweed River in CAD, and all the survey points with a depth of less than $3.5 \mathrm{~m}$ were identified. The trigger volumes for the entrance and inner ebb shoal reservoirs were defined as $140,000 \mathrm{~m}^{3}$ and $280,000 \mathrm{~m}^{3}$ respectively.

The two models were run with a constant longshore sand inflow of $500,000 \mathrm{~m}^{3} /$ year, and the total dredging volume split between the inner ebb shoal (80\%) and entrance (20\%) as before. Results from the inner ebb shoal (Figure 7) show that navigability of the Tweed River entrance can be maintained with annual dredging. If dredging only occurs every two years, the entrance will have compromised navigability for approximately $25 \%$ of the time.

Letitia Spit showed slight signs of recovery in these two scenarios. If further erosion is to be avoided at Letitia Spit, the maximum allowable pumping volume was found to be approximately $325,000 \mathrm{~m}^{3} /$ year on average.

\section{DISCUSSION}

The main strength of the Reservoir model is its simplicity and transparency, making it easy for the user to identity anomalies in results. Much of the model data must be entered manually however, which can make model validation quite time-consuming.

This study was undertaken using Inlet Reservoir Model version 1.2. The program is under continued development by the U.S. Army Corps of Engineers, and at the time of writing the last available release was version 2.0.

One type of data that the TRESBP does not record is the exact locations of dredging campaigns, and how much material is removed from each particular part of the entrance. This is why the 80:20 dredging ratio between the entrance and inner ebb shoal could not be verified. If precise dredging locations were known it would be possible to divide the reservoirs into smaller packets for more detailed analysis.

A thorough sensitivity analysis of the results was not completed for this study, however the following parameters were assessed during validation of the model: reservoir boundary locations, volume datum/initial volume, equilibrium volume, inflow rate, coupling coefficients and pathway definitions. The model seems to be most sensitive to changes in the inflow rate and equilibrium volume parameters.

Wave-driven longshore transport was assumed to be the dominant force in the evolution of the Tweed River entrance morphology. Cross-shore sediment transport and alluvial transport from the lower Tweed were assumed to be insignificant.

This study was originally undertaken in 2009. At the time of writing, no dredging has occurred in the Tweed River entrance since 2008, although there is some periodic dredging of the lower Tweed River (TRESBP, 2012). This is partially due to the low energy wave climate since 2009.

\section{CONCLUSION}

The hard engineering approach to coastal management at the Tweed River entrance has caused severe erosion and accretion problems in the region. The Tweed River Entrance Sand Bypassing Project was conceived to restore stability to the coastline by mimicking the natural northward flow of sediment, and maintain a navigable channel within the lower Tweed River.

The coastal management regime at the Tweed River entrance was modelled using the U.S Army Corps of Engineers Inlet Reservoir Model. Pumping, dredging and natural longshore sediment transport data were used to validate the model against bathymetric surveys. The model reproduced the behaviour of the inlet well for the period from 2000 to 2009.

The Inlet Reservoir Model works best when there are large quantities of validation data available for the inlet. The Tweed River entrance was an ideal location to apply the model, due to the vast quantity of 
measurements and careful record keeping of the Tweed River Entrance Sand Bypassing Project team.

The most compelling feature of the Reservoir model is its simplicity and transparency. By the time the reservoir locations, equilibrium volumes, input rates, pathways and coupling coefficients have been defined, the operator has formed an intimate relationship with the coastal inlet, and can immediately identify major errors in the model results.

\section{ACKNOWLEDGEMENTS}

The authors would like to thank the Tweed River Entrance Sand Bypassing Project team, particularly George Elias (NSW Department of Lands) and Catherine Acworth (Queensland Government Hydraulics Laboratory) for providing all of the data used in this study.

\section{REFERENCES}

Bannon, K. 2008. The Construction and Analysis of an Estuary Entrance Model for the Tweed River, $N S W$. Undergraduate Honours Thesis, School of Civil and Environmental Engineering, University of New South Wales, Sydney.

Boak, E. H., Jackson, L. A., McGrath, J. E., and Brosnan, M. P. 2001. An overview of Gold Coast coastal management 1960-2001. In Proceedings of 15th Australasian Conference on Coastal and Ocean Engineering, Gold Coast, Australia.

Delft Hydraulics Laboratory 1970. Gold Coast, Queensland, Australia : coastal erosion and related problems: coastal erosion and related problems. Delft Hydraulics Laboratory, Delft, Netherlands.

Department of Land and Water Conservation and Queensland Environmental Protection Agency 2001. Tweed River Entrance Sand Bypassing Project: summary of contracts. Department of Land and Water Conservation, Sydney.

Dyson, A., Lawson, S., Victory, S., Boswood, P., Mahon, B., Trucchi, L., and Cummings, P. 2003. Tweed River entrance sand bypassing project post-commissioning coastal behaviour. In Proceedings of 16 th Australasian Conference on Coastal and Ocean Engineering, Auckland, New Zealand.

Howe, D. 2009. Coastal Entrance Dynamics - Reservoir Model Applied to Tweed. Undergraduate Honours Thesis, School of Civil and Environmental Engineering, University of New South Wales, Sydney.

Hyder, Patterson Britton and Partners, and WBM Oceanics Australia 1997. Tweed River entrance sand bypassing project, permanent bypassing system, environmental impact statement-impact assessment study, Report No. $9706236-4 D$.

Kraus, N. 2000. Reservoir model of ebb-tidal shoal evolution and sand bypassing. Journal of Waterway, Port, Coastal, and Ocean Engineering, 126(6):305-313.

Lawson, S., McMahon, J., and Boswood, P. 2000. Environmental management of the construction and operation of a sand bypassing system at the Tweed River entrance. In Proceedings of 15th Australasian Conference on Coastal and Ocean Engineering, Gold Coast, Australia.

Murray, R., Brodie, R., Porter, M., and Robinson, D. 1996. Tweed River sand bypass: concepts and progress. Proceedings of 25th International Conference on Coastal Engineering, Orlando, Florida.

Pattearson, C. C. and Patterson, D. C. 1983. Gold Coast longshore transport. In Proceedings of 6th Australasian Conference on Coastal and Ocean Engineering, Brisbane, Australia.

Pound, M. and Leppert, S. 2001. Design and construction aspects of the Tweed River entrance sand bypassing project. In Proceedings of 15th Australasian Conference on Coastal and Ocean Engineering, Gold Coast, Australia.

Queensland Government 1998. Tweed River Entrance Sand Bypassing Project Agreement Act 1998.

TRESBP 2012. Sand delivery. Tweed River Entrance Sand Bypassing Project, www.tweedsandbypass. nsw.gov.au/sand_delivery [Accessed 19-07-2012]. 